\title{
O Protagonismo da Escola Técnica Nacional na Formação de Professores: o que dizem os monumentos e a Matemática
}

Elmha Coelho Martins Moura'

'Universidade Federal da Integração Latino-Americana (UNILA), Foz do Iguaçu/PR - Brasil

RESUMO - O Protagonismo da Escola Técnica Nacional na Formação de Professores: o que dizem os monumentos e a Matemática. Este artigo tem por finalidade discutir a Escola Técnica Nacional (ETN) em seu protagonismo na formação de professores para o Ensino Técnico e algumas das ideias que circulavam na época, desde suas origens até o período que culminou com o funcionamento da ETN. Para essa discussão foram utilizadas as seguintes fontes de pesquisa: o monumento arquitetônico, a antiga sede do Ministério da Educação e Saúde (MES), documentos do arquivo da Escola, e do arquivo da Casa Museu de Villa-Lobos, os Boletins da CBAI, o livro didático Matemática e a obra traduzida pela CBAI Psicologia para professores do ensino industria'. Analisar esses Documentos/Monumentos permitiu verificar alguns elementos dessas ideias circulantes: a eugenia, o nacionalismo e a finalidade da Matemática.

Palavras-chave: Ensino Industrial. Formação de Professores. Monumentos/Documentos.

ABSTRACT - The Protagonism of the National Technical School in Teacher Education: what monuments and mathematics say. This article aims to discuss the National Technical School (ETN) in its protagonism in the formation of teachers for Technical Education and some of the ideas that circulated at the time, from its origins to the period that culminated in the operation of ETN. For this discussion, the following research sources were used: the architectural monument, the former headquarters of the Ministry of Education and Health (MES), documents from the School's archive, and the archive of the Casa Museu de Villa-Lobos, the CBAI Bulletins, the textbook Mathematics and the work translated by CBAI Psicologia para Profesores do ensino industrial. Analyzing these Documents / Monuments allowed to verify some elements of these circulating ideas: eugenics, nationalism, and the purpose of Mathematics.

Keywords: Industrial Education. Teacher training. Documents/Monuments. 
O Protagonismo da Escola Técnica Nacional na Formação de Professores

\section{Introdução}

A história do ensino técnico está correlacionada com o processo de industrialização, na necessidade de especializar mão de obra para trabalhar no novo modo de produção, a indústria, que se desenvolvia em diversos pontos do planeta. Para atuar nesse ensino, as escolas criadas no Brasil, careciam de professores qualificados. Formar professores para lecionarem no ensino industrial, sempre foi um desafio para o governo federal de diversas gestões. Na tentativa de encontrar uma solução mais duradoura, foi criada, na capital brasileira, Rio de Janeiro (RJ), uma Escola Normal para o ensino industrial, a Escola Técnica Nacional (ETN), dentre as suas finalidades constava a de formar e qualificar professores para esse ramo de ensino.

A Escola teve sua origem em 1917 com o nome Escola Normal de Artes e Ofícios Wenceslau Braz e findou a sua função de formar professores em 1978, quando passou a ser denominada Centro Federal de Educação Tecnológica Celso Suckow (CEFETRJ), unidade Maracanã.

A Escola Técnica Nacional foi protagonista na formação de professores para rede federal de ensino profissionalizante, presente nas escolas técnicas e industriais das capitais brasileiras. Localizada em um dos centros de decisões do País, o Rio de Janeiro, a Escola também, ocupava um lugar de discussões e decisões do ensino industrial, ou seja, constituiu-se como um espaço efervescente de circulações de ideias e movimentações pedagógicas.

Nesse sentido, este texto tem a finalidade de discutir o papel da ETN na formação de professores e algumas das ideias que ali circulavam. Para tanto, foram utilizados monumentos arquitetônicos, como a antiga sede do Ministério da Educação e Saúde (MES) e documentos do arquivo da Escola, e do arquivo da Casa Museu de Villa-Lobos, os Boletins da Comissão Brasileiro-Americana de Educação Industrial (CBAI, 1947), o livro didático Matemática e a obra traduzida pela CBAI Psicologia para professores do ensino industrial. Tudo analisado sob a perspectiva do conceito Documentos/Monumentos de Le Goff (1992, p. 545), ao afirmar que todo documento tem em si caráter de monumento. "Só na análise do documento enquanto monumento permite a memória coletiva recuperá-lo e ao historiador usá-lo cientificamente, isto é, com pleno conhecimento de causa".

É possível perceber o uso da nomenclatura monumento para obras literárias. Vejamos, no dicionário de Faria (1962) monumento do latim Monumentum é o que traz à lembrança de alguma coisa, penhor, daí várias acepções particulares: túmulo, estátua, inscrições, lápide, templo, obra literária, sinal, indício (de reconhecimento). No dicionário Aurélio on line de 2015, além das estátuas, lápides, túmulos, entre outros, Monumento é também, qualquer obra intelectual ou material que pelo seu alto valor passa a posteridade.

Assim, nessa perspectiva, Monumentos também são Documentos e, de acordo com Moura (2016), trata-se de objetos de valor histórico e/ ou artístico, estabelecidos por regime jurídico o mérito de ser conserva- 
do. Neste trabalho, tais fontes de pesquisas, possibilitaram verificar na ETN, em seu aspecto de formação de professores, ideias que circularam a respeito da Matemática, das pedagogias, como também, as que circulavam em um contexto externo aos muros da Escola, como eugenia e nacionalismo.

\section{O Protagonismo da Escola Técnica Nacional (ETN)}

Localizada no Rio de Janeiro, capital do Brasil na época de sua criação, a Escola Técnica Nacional se destacou das demais escolas técnicas do País, pela sua localização e como o próprio nome induz, por produzir modelos para as demais escolas da rede federal de ensino profissionalizante. O primórdio desse ensino se deu em 1909, pelo Decreto n. 7.566 que determinou a criação, nas capitais dos Estados da União, de Escolas de Aprendizes e Artífices para o ensino profissional primário e gratuito. Mantidas pelo Governo Federal, essas escolas se destinavam “[...] não só a habilitar os filhos dos desfavorecidos da fortuna com o indispensável preparo technico e intellectual, como fazê-los adquirir hábitos de trabalho profícuo, que os afastará da ociosidade ignorante, escola do vicio e do crime" (Brasil, 1909, p. 1).

As escolas de aprendizes e artífices, destinada a formar jovens trabalhadores, para as indústrias de um Brasil recém republicano, possuía o seu currículo dividido em disciplinas de Cultura Geral, comum a todos os cursos, Português, Inglês ou Francês, Matemática, Física, Química, História Natural, História Universal, Geografia Geral e as disciplinas de Cultura Técnica, específicas para cada curso, porém em todos havia a disciplina de Tecnologia do Ofício e Desenho Técnico destinado também ao ofício. Todos os cursos técnicos incluíam as disciplinas de Higiene Industrial, de Organização do Trabalho e de Contabilidade Industrial.

Para esse novo ensino foi imprescindível formar professores para atuarem no alicerce desse tipo de educação, segundo Moura (2018), a oficina e as disciplinas de cultura técnica. Uma carência nacional, que levou o prefeito Amaro Cavalcanti (1849-1922) do Rio de Janeiro a criar, pelo Decreto 1800 de 1917, a Escola Normal de Artes e Ofícios Wenceslau Braz com a finalidade de formar professores, mestres e contramestres para os vários institutos e escolas profissionais, além ainda de preparar professores de trabalhos manuais para escolas primárias municipais.

Em 1919, em uma negociação com o Governo Federal, de acordo com Fonseca (1961), a Escola foi transferida para a União, no intuito de minimizar a falta de professores. No ano de 1937, a Escola Normal de Artes e Ofícios Wenceslau Braz teve suas atividades encerradas em função da Lei n. ${ }^{\circ}$ 378, de 13 de janeiro de 1937, que determinava a mudança das Escolas de Aprendizes Artífices para Liceus Industriais. O Palacete Leopoldina, que abrigava a Escola Wenceslau Brás, foi demolido para ceder lugar à construção de um novo edifício. Porém, após a conclusão das obras, cinco anos depois, o novo prédio teve a sua denominação alterada para Escola Técnica Nacional (ETN), pois, entrava em vigor a 
O Protagonismo da Escola Técnica Nacional na Formação de Professores

Lei Orgânica do Ensino Industrial, com o Decreto-Lei n.4073 de 30 de janeiro de 1942 (Brasil, 1942).

A Lei Orgânica organizou o ensino industrial em dois ciclos: o primeiro ciclo abrangia o ensino industrial básico (antigo ginásio), o ensino de mestria, o ensino artesanal e a aprendizagem; o segundo ciclo compreendia o ensino técnico (antigo secundário) e o ensino pedagógico. As alterações dessa Lei trouxeram unidade legislativa às escolas profissionalizantes brasileiras, permitiram aos portadores de diploma do ensino técnico secundário acesso às universidades, extinguiram os Liceus Industriais e as Escolas de Aprendizes Artífices, modificaram a finalidade do ensino profissionalizante que passou a atender aos interesses do trabalhador, da empresa e da nação.

Com nova configuração, a ETN manteve o seu caráter de formar professores para o ensino industrial, em obediência ao parágrafo único do artigo $4^{\circ}$ do Decreto-Lei $N^{\circ} 4073$ que anuncia: "Cabe ainda ao ensino industrial formar, aperfeiçoar ou especializar professores de determinadas disciplinas próprias desse ensino, e administradores de serviços a esse ensino relativos". Em sua função, a ETN ofereceu cursos em todas as modalidades do primeiro e segundo ciclo e também os cursos de formação, aperfeiçoamento e especialização de professores.

É importante ressaltar que a formação de professores era destinada aos que ministravam as disciplinas de cultura técnica. Nesse cenário, um importante aliado se destaca: a Comissão Brasileira Americana de Educação Industrial (CBAI); formada por técnicos brasileiros e norte-americanos, que atuaram em conjunto, desenvolvendo relações de intercâmbio, treinamentos e diversas atividades da educação industrial de interesse mútuo.

A CBAI, de acordo com Falcão e Cunha (2009), surgiu em função da busca pelo Ministério da Educação por profissionais qualificados. Nessa busca, em 1942, foram realizadas as primeiras contratações de docentes estrangeiros, suíços e norte-americanos. Porém, era necessária uma solução mais estável. Em 1943 o então Ministro da Educação, Gustavo Capanema, participou da I Conferência de Ministros e Diretores de Educação das Repúblicas Americanas, realizada em Havana. Nesse evento, Gustavo Capanema em um entendimento com as autoridades educacionais norte americanas - representadas pela Inter American Fundacion Inc, subordinada ao Office of Inter American Affairs - aproximou o Brasil e os Estados Unidos mediante intercâmbio de educadores, ideias e métodos pedagógicos. Assim, surge em 1946, como parte do acordo de cooperação dos Estados Unidos para com o ensino brasileiro, a Comissão Brasileira Americana de Educação Industrial (CBAI), que atuaria como executor de programa de cooperação educacional.

A Escola Técnica Nacional, segundo Brito e Moura (2019), encontrou dificuldades de colocar em funcionamento os Cursos Pedagógicos, previstos na legislação em duas modalidades: Didática do Ensino Industrial e Administração do Ensino Industrial, ambos com duração de um ano. O curso de Didática foi implantado somente em 1954 (Bra- 
sil, 1954). Porém, tal situação não impediu que a Escola qualificasse os professores mediante ofertas de outros cursos como os: Cursos Avulsos, Cursos Extraordinários de Especialização e os Cursos de Férias. Muitas dessas formações aconteceram em parceria com a CBAI.

Os cursos de férias oferecidos pela CBAI, segundo Brito e Moura (2019), aconteciam em duas etapas:

\begin{abstract}
Na primeira, os professores selecionados concentravamse na Escola Técnica Nacional, para revisar conteúdos de conhecimentos gerais e técnicos, estudo da língua inglesa e atualização e ampliação dos conhecimentos sobre a vida social no Brasil. Na segunda etapa, aconteceria nos Estados Unidos uma espécie de estágio: a permanência era de um ano, estagiando seis meses em escolas profissionais, três meses nas indústrias para se aperfeiçoarem nos ofícios, e três meses frequentando um curso pedagógico. No retorno ao Brasil os professores-alunos escreviam suas experiências profissionais no Boletim da CBAI (Brito; Moura, 2019, p. 208).
\end{abstract}

Os Cursos de Férias eram realizados anualmente nas capitais: Rio de Janeiro, São Paulo, Porto Alegre e Recife, cidades consideradas estratégicas para o deslocamento dos professores da rede federal de ensino profissionalizante. A CBAI ofertava diversos cursos de ofício de madeira (Marcenaria e Carpintaria), de Metal (Mecânica de Máquinas, Serralheria e Solda), de Desenho, de Metodologia do Ensino Industrial, de Organização de Séries Metódicas e revisão de conteúdo. As atividades dividiam-se em teóricas, práticas e de visitas. As aulas práticas aconteciam nas indústrias de São Paulo e do Rio de Janeiro.

Para o Curso Pedagógico, de acordo com a Lei Orgânica do Ensino Industrial, o candidato deveria mostrar o comprovante de vacinação e não ser portador de nenhuma doença contagiosa e de estar vacinado. As condições para admissão eram: ter concluído qualquer dos cursos de mestria ou qualquer dos cursos técnicos e ter sido aprovado nos exames vestibulares. Os professores aprovados, deveriam também ter trabalhado na indústria durante três anos no mínimo. Esse era o perfil de um profissional ao qual lhe faltava apenas o Curso de Didática para o tornar apto a lecionar na rede federal de ensino profissionalizante, com o diploma de licenciado. O Curso Pedagógico era um programa organizado sob os alicerces educacionais da psicologia, história, metodologias de ensino e, ainda do ofício, com características próprias do ensino industrial.

A Escola Técnica Nacional também ofereceu juntamente com a CBAI, o curso de Training Within Industry (TWI), conhecido como a pedagogia do ensino industrial. Esse método de treinamento foi trazido ao Brasil, em 1950, pela CBAI, de maneira a contribuir para o aumento da produção industrial do País. De acordo com Moura (2013), este método foi aplicado nas escolas técnicas e industriais, e nas diversas indústrias de eletroeletrônicos, de calçados, metalúrgicas, pneumáticas, automotivas entre outras presentes nos principais estados brasileiros. A ETN 
O Protagonismo da Escola Técnica Nacional na Formação de Professores

abrigou diversas reuniões dos dirigentes das indústrias e escolas técnicas, que aplicaram em seus estabelecimentos o TWI, com resultados expressivos.

A Escola Técnica Nacional teve a sua nomenclatura alterada diversas vezes, em 1965, passou a chamar-se Escola Técnica Federal da Guanabara, devido à mudança da capital federal para Brasília. Em 1967, foi denominada de Escola Técnica Federal Celso Suckow da Fonseca, em uma homenagem póstuma ao seu primeiro diretor e, em 1978, foi transformada em Centro Federal de Educação Tecnológica Celso Suckow da Fonseca, mantendo-se com essa denominação até a atualidade.

Essas mudanças não alteraram a sua condição de Escola Técnica e nem seu protagonismo em formar e qualificar professores para o Ensino Técnico. Mas, nas suas nomenclaturas constavam os registros de acontecimentos significativos para sua comunidade escolar: ser Nacional, ser Guanabara e a importância do diretor Celso Suckow da Fonseca.

\section{Circulação de ideias/Movimentação pedagógica}

O nome Escola Técnica Nacional abrigou mais que a função de uma instituição de ensino, descrita em Decretos, Regimentos e Normativas, ele, o nome, carregou um conjunto de ideias constituídas por diversos agentes, que podem ser analisadas/interpretadas com o uso de diversas fontes de pesquisas. Nesse sentido, foram analisados alguns Documentos/Monumentos: a Estátua o Homem Brasileiro, o Edifício do Ministério da Educação e Saúde, os Boletins da CBAI, o livro didático de matemática, literaturas, documentos do arquivo da ETN e do arquivo da Casa Museu de Villa-Lobos, a fim de expressar algumas circulações de ideias e movimentação pedagógica, intra/extramuro, dessa Escola.

Vejamos, a construção da estátua do Homem Brasileiro, pelo Ministro da Educação e Saúde Gustavo Capanema, durante o Estado Novo do Presidente Getúlio Vargas (1937-1945), compreendeu aproximadamente o período de fechamento da Escola Normal de Artes e Ofícios Wenceslau Braz, abertura da ETN e criação da CBAI. Segundo Moura (2016), a estátua tinha por finalidade representar as características físicas do homem brasileiro no futuro, bem como, as qualidades de um homem inteligente, culto ou trabalhador. O monumento segundo Knauss (1999), ocuparia os jardins do edifício da futura sede, em construção, do Ministério da Educação e Saúde (MES), estátua e prédio deviam harmonizar os mesmos objetivos: a formação do homem brasileiro.

Os idealizadores da estátua eram quatro professores: Oliveira Vianna, Rocha Vaz, Roquette Pinto e Froes da Fonseca que não chegaram a um consenso sobre as características físicas do homem brasileiro do futuro. Mas, todos consideraram que as características predominantes desse brasileiro seria o branco moreno, com cabelo liso e escuro assim como a íris dos olhos. De acordo com Moura (2016), os idealizadores confiavam no futuro branco do País, que representava uma aproximação às supostas virtudes do homem europeu e, para isso, era necessário investir em uma educação e saúde voltadas para a formação do homem 
brasileiro branco e virtuoso, aos moldes da virtude europeia. Tais conclusões consistem no fato de que esses intelectuais fizeram parte do movimento eugênico brasileiro. Em meio as dissensões e divergências, a estátua do Homem Brasileiro não foi construída.

Em 1944, no jardim do MES aconteceu um ato comemorativo do lançamento de da pedra fundamental, pela construção de uma nova estátua: o Monumento da Juventude Brasileira. $\mathrm{O}$ ato foi presidido pelo Ministro Gustavo Capanema e toda a solenidade foi acompanhada por um conjunto musical, coro estudantil e banda da polícia militar, regidos pelo maestro Villa-Lobos (1887-1959), com apresentação de hinos e cantos patrióticos. Heitor Villa-Lobos, maestro e compositor brasileiro, foi um dos grandes edificadores do nacionalismo estadonovista, via educação musical. Em seu livro, A música nacionalista no Governo Getúlio Vargas, Villa-Lobos (1941) descreve a importância da formação de uma consciência musical brasileira, pelo Canto Orfeônico nas escolas, por totalizar um conjunto de fatores educacionais complexos de civismo, de disciplina coletiva e de constituição de uma unidade da cultura nacional brasileira.

O antigo edifício do Ministério da Educação e Saúde, conhecido atualmente como o Palácio da Cultura Gustavo Capanema, representou segundo Moura (2016), as ideias modernistas da época no que se refere as construções arquitetônicas. Por essa razão, foi considerada a primeira edificação monumental, destinada à sede de serviços públicos a seguir os rigores e os princípios da moderna arquitetura, o que lhe rendeu reconhecimento internacional. Havia a preocupação do ministro Capanema em integrar prédio e monumento com as artes plásticas, fato que foi considerado fundamental para a elaboração e conclusão de todo o espaço ministerial. Na exposição permanente, no Palácio Capanema, há a seguinte frase de autor não identificado: "Capanema imaginava a sede do Ministério, a um só tempo, como um local de trabalho e uma casa de arte. Assim, o prédio só foi considerado concluído após a incorporação das artes plásticas". Sendo algumas delas obras de Candido Portinari, Oscar Niemeyer, Celso Antônio, Bruno Giorgi, Adriana Janacópulos, Jacques Lipschitz, e Burle Marx.

Os acontecimentos da não-construção da estátua do Homem Brasileiro, o ato comemorativo do lançamento da pedra fundamental do Monumento da Juventude Brasileira com a presença de Villa-Lobos e a construção da sede do Ministério da Educação e Saúde ocorreram na cidade do Rio de Janeiro, mas, tiveram abrangência nacional. Esses eventos fizeram respectivamente circular ideias de eugenia, nacionalismo, modernidade/arte, todas vinculadas a Educação de jovens brasileiros nas escolas de todo o país. Nesse contexto, veremos algumas ideias que circulavam na Escola Técnica Nacional.

É possível perceber, em uma análise nos documentos dos arquivos dessa Escola, um espaço físico de extrema importância, considerado o cerne do ensino industrial: a oficina. Segundo Moura (2018), era um lugar de máquinas, equipamentos, técnicas de manejos, como também, de disciplina, organização, planejamento desempenho, produtividade 
e eficácia. Tratava-se de um espaço onde prevalecia os conhecimentos técnicos, próprios de cada oficina, aliados aos conhecimentos de Desenho, Matemática e Geometria. Eram nas disciplinas de cultura técnica, que compunham o conhecimento técnico, que o ensino industrial carecia de professores qualificados.

Os trabalhos produzidos nas oficinas eram apresentados anualmente em uma exposição, com julgamento do grau de adiantamento dos alunos e premiação dos melhores trabalhos. Esse tipo de exposição, no cenário internacional, se tornou a partir de 1950 uma competição conhecida como WorldSkills Internacional, um verdadeiro campeonato de práticas de oficina na formação profissional.

Nos Boletins da CBAI (1947-1962) eram publicadas as notícias e ideias que circulavam no Ministério da Educação, nas indústrias, na ETN e demais escolas técnicas brasileiras, todos os seus artigos referiam-se diretamente às situações ligadas ao ensino industrial. Publicavam nesse periódico, os técnicos da CBAI, os professores de cultura técnica, autoridades da Educação como Anísio Teixeira, diretores das escolas etc. Os textos versavam sobre diversas temáticas tais como: reformas nos prédios escolares; currículos; cursos de formação de professores; pedagogia TWI; segurança na oficina e no trabalho; higiene, saúde e doenças no trabalho; conteúdo das práticas de oficina; conteúdos de matemática, desenho, física e química, aplicados ao funcionamento de máquinas, motores e equipamentos.

O TWI foi um método eficaz de treinamento para o trabalho nas indústrias, mas não foi a única ideia "pedagógica" a circular nas escolas federais. A Psicologia também surgiu como importante aliada nesse processo educativo profissionalizante. A CBAI traduziu, entre outras literaturas técnicas, o livro Psicologia para professores do ensino industrial (Roslow; Weaver, 1949), destinado para todos que desejavam ingressar no setor de educação profissional.

Roslow e Weaver consideram a psicologia como uma ciência que estuda o comportamento do indivíduo na sua adaptação ao meio ambiente. Segundo os autores, o ensino industrial diz respeito ao ensino de aprendizagem de habilidades manuais, e não condiz com método passivo. Eles descrevem dois métodos de aprendizagem: o método de partes ou analítico e o método global, que serão utilizados, conforme o conteúdo a ser ensinado.

O método de partes ou analítico implica a divisão da matéria em partes menores, ou unidades, e na aprendizagem dessas partes em ordem consecutivas em uma relação com o todo. O método é necessário para evitar perda de tempo e desânimo, porque pode parecer ao aluno que a tarefa seja longa e complicada. As subdivisões são permissíveis e devem ser feitas com coerência. Um exemplo desse método, dado pelos autores, é a sua utilização no corte e costura. Uma moça aprende a cortar pelo molde, a fazer por partes a vestimenta. Embora faça as atividades separadamente, a aluna compreenderá a visão geral do que deve ser feito e a relação existente entre as partes. 
O método global implica na repetição de uma série completa de atividade até obter-se um rendimento satisfatório. Por vezes, não é um método prático, porque faz perder tempo e material. Não há necessidade de fazer a correlação entre as partes ensinadas em separado. Um exemplo, mencionado pelos autores, é caso do motorista que, logo no início do treinamento, deve executar todas as operações necessárias que resultem na movimentação, na direção de um automóvel. O treinamento de um mecânico pode ser feito por esse método, nas operações de ajustagem de máquinas, perfuração, limagem, torneamento, etc.

A escolha do melhor método a ser utilizado em uma atividade a ser realizada, dependia de cada situação, e se poderia considerar necessária a aliança entre os dois métodos para o melhor desempenho e rendimento da tarefa a ser concluída.

A Escola Técnica Nacional elaborou no ano de 1967 um livro de Matemática exclusivamente brasileiro. Era uma obra não traduzida, de autoria do professor de Matemática Arlindo Clemente da ETN. O autor adverte nas primeiras páginas de seu livro Matemática, que considera o Curso Técnico um curso final e não um curso preparatório para as escolas de engenharias, embora seja legitimo o direito de os alunos tentarem os exames de vestibulares, prosseguindo com os seus estudos. Essa advertência era um lembrete de que as escolas técnicas não preparavam para aprovação no vestibular, mas para a formação de técnicos.

\section{Considerações finais}

O que dizem os monumentos e a Matemática?

Os monumentos, sendo eles arquitetônicos e documentos possibilitaram discutir um pensamento da época, a busca pela modernização do País, com uma forte tendência nacionalista. Ideias que circulavam no período e que foram ilustradas pelo ambiente do lançamento da pedra fundamental do Monumento da Juventude Brasileira, bem como no projeto e construção do Edifício da sede do Ministério da Educação e Saúde. Mesmo, as discussões desenvolvidas no projeto do monumento não construído, a Estátua do Homem Brasileiro, são interessantes para analisar o pensamento vigente na época, a eugenia. Tais ideias permeavam no contexto em que se desenvolveu o ensino técnico e a formação de professores para esse ensino.

O surgimento da Escola técnica Nacional desde os primórdios a partir Escola Normal de Artes e Ofícios Wenceslau Braz, acompanhou um processo de a industrialização do País. A Matemática nessas escolas, priorizando atender a disciplina Desenho e o Ensino Técnico como um fim e não um meio para a entrada em um Curso Superior, revelava essa tendência. A preocupação em criar um corpo docente capacitado para o Ensino Técnico, através do Curso Pedagógico e Cursos de Férias mostra uma consonância com a CBAI, a "Pedagogia" TWI e a Psicologia do ensino industrial que ilustram uma preocupação com modernização desse ensino.

Educação \& Realidade, Porto Alegre, v. 46, n. 2, e112166, 2021. 
Pesquisar o ensino técnico e o protagonismo da ETN na formação do professor para o ensino técnico profissionalizante, bem como a matemática voltada para esse ensino, ajuda-nos a visualizar um aspecto pedagógico do processo de industrialização do País.

Recebido em 15 de março de 2021 Aprovado em 19 de maio de 2021

\section{Referências}

BRASIL. Decreto no. 7.566. Créa nas capitaes dos Estados da Escolas de Aprendizes Artífices, para o ensino profissional primario e gratuito. Rio de Janeiro, 1909. Disponível em: <http://portal.mec.gov.br/setec/arquivos/pdf3/decreto_7566_1909.pdf>. Acesso em: 02 jun. 2020.

BRASIL. Decreto no. 4.073. Lei Orgânica do Ensino Industrial. Diário Oficial da União, Rio de Janeiro, 1942.

BRASIL. Decreto no. 8.680. Dispõe sobre os Cursos Pedagógicos de Ensino Industrial e seu funcionamento. Diário Oficial da União, Rio de Janeiro, 1954.

BRITO, Arlete de Jesus; MOURA, Elmha Coelho Martins. Formação de professores nas escolas Wenceslau Braz e Técnica Nacional: o ensino de matemática. Educação, Porto Alegre, PUCRS, v. 42, n. 2, p. 202-212, 2019. Disponível em: <https://doi.org/10.15448/1981-2582.2019.2.33900 >. Acesso em: 02 jun. 2020.

CBAI. Comissão Brasileiro-Americana de Educação Industrial. Boletins de 1947-1962. Rio de Janeiro, 1947.

FALCÃO, Luciane Quintanilha; CUNHA, Luiz Antônio. Ideologia, Política e Educação: A CBAI (1946/1962). Revista Contemporânea de Educação, Rio de Janeiro, v. 4, n. 7, jan./jul. 2009. Disponível em: <https://revistas.ufrj.br/index. php/rce/article/view/1579/1427>. Acesso em: 14 mar. 2021.

FARIA, Ernesto. Dicionário escolar latino-português. Brasília: Ministério da Educação e Cultura, 1962.

FONSECA, Celso Suckow. História do Ensino Industrial no Brasil. Rio de Janeiro: ETN, 1961

LE GOFF, Jacques. História e Memória. Tradução Bernardo Leitão et al. Campinas: Editora da UNICAMP, 1992.

MOURA, Elmha Coelho Martins. The TWI pedagogy in Brazilian industry in the early years of the 1950s. In: INTERNATIONAL CONGRESS OF HISTORY OF SCIENCE, TECHNOLOGY AND MEDICINE (ICHSTM), 24., 2013, Manchester Proceedings... Manchester, 2013.

MOURA, Elmha Coelho Martins. O Ensino de Matemática em duas escolas profissionalizantes: Brasil e Portugal, no período de 1942 a 1978. 2016. Tese (Doutorado em Educação Matemática) - Programa de Pós-Graduação em Educação Matemática, Universidade Estadual Paulista "Júlio de Mesquita Filho", Rio Claro, 2016.

MOURA, Elmha Coelho Martins. Um olhar sobre a oficina na formação do técnico em escolas profissionalizantes do Brasil e de Portugal no período de 1942 a 1978. Revista Eventos Pedagógicos, Sinop, v. 9, n. 2, p. 767-787, ago./out. 2018. Disponível em: <http://sinop.unemat.br/projetos/revista/index.php/eventos/ issue/view/130/showToc >. Acesso em: 14 mar. 2021. 
ROSLOW, Sidney; WEAVER, Gilbert G. Psicologia para professôres do ensino industrial. Biblioteca do ensino industrial, série B, v. 4. Rio de Janeiro: MES/ CBAI, 1949.

VILLA-LOBOS, Heitor. A música nacionalista no governo Getúlio Vargas. Rio de Janeiro D.F.: DIP, 1941.

Elmha Coelho Martins Moura é doutora em Educação Matemática pela Universidade Estadual Paulista 'Júlio de Mesquita Filho' (UNESP). Professora da Universidade Federal da Integração Latino-americana (UNILA), Campus Universitário de Foz do Iguaçu, Instituto Latino-Americano de Ciências da Vida e da Natureza (ILACVN), Curso Matemática.

ORCID: https://orcid.org/0000-0001-9345-4236

E-mail: elmha.moura@unila.edu.br

Editor-responsável: Luís Armando Gandin

Este é um artigo de acesso aberto distribuído sob os termos de uma Licença Creative Commons Atribuição 4.0 Internacional. Disponível em: <http:// creativecommons.org/licenses/by/4.0>. 